\title{
Corticotropin-releasing hormone links pituitary adrenocorticotropin gene expression and release during adrenal insufficiency
}

\author{
Louis J. Muglia, ${ }^{1,2,3}$ Lauren Jacobson, ${ }^{4}$ Christina Luedke, ${ }^{4}$ Sherri K. Vogt, ${ }^{1}$ \\ Michele L. Schaefer, ${ }^{4}$ Pieter Dikkes, ${ }^{5}$ Shoko Fukuda, ${ }^{6}$ Yoko Sakai, ${ }^{6}$ \\ Toshihiro Suda, ${ }^{6}$ and Joseph A. Majzoub ${ }^{4}$ \\ ${ }^{1}$ Department of Pediatrics, \\ ${ }^{2}$ Department of Molecular Biology and Pharmacology, and \\ ${ }^{3}$ Department of Obstetrics and Gynecology, Washington University School of Medicine, St. Louis, Missouri, USA \\ ${ }^{4}$ Division of Endocrinology, and \\ ${ }^{5}$ Department of Neurology, Children's Hospital, Boston, Massachusetts, USA \\ ${ }^{6}$ Third Department of Medicine, Hirosaki University School of Medicine, Hirosaki, Japan
}

Address correspondence to: Joseph A. Majzoub, Division of Endocrinology, Children's Hospital, 300 Longwood Avenue, Boston, Massachusetts 02115, USA. Phone: (617) 355-6421; Fax: (617) 355-3741; E-mail: majzoub@a1.tch.harvard.edu.

Lauren Jacobson's present address is: Department of Pharmacology and Neuroscience,

Albany Medical College, Albany, New York, USA.

Received for publication September 16, 1998, and accepted in revised form March 14, 2000.

Corticotropin-releasing hormone $(\mathrm{CRH})$-deficient $(\mathrm{KO})$ mice provide a unique system to define the role of CRH in regulation of the hypothalamic-pituitary-adrenal (HPA) axis. Despite several manifestations of chronic glucocorticoid insufficiency, basal pituitary proopiomelanocortin (POMC) mRNA, adrenocorticotrophic hormone (ACTH) peptide content within the pituitary, and plasma ACTH concentrations are not elevated in CRH KO mice. The normal POMC mRNA content in KO mice is dependent upon residual glucocorticoid secretion, as it increases in both KO and WT mice after adrenalectomy; this increase is reversed by glucocorticoid, but not aldosterone, replacement. However, the normal plasma levels of ACTH in CRH KO mice are not dependent upon residual glucocorticoid secretion, because, after adrenalectomy, these levels do not undergo the normal increase seen in $\mathrm{KO}$ mice despite the increase in POMC mRNA content. Administration of CRH restores ACTH secretion to its expected high level in adrenalectomized CRH KO mice. Thus, in adrenal insufficiency, loss of glucocorticoid feedback by itself can increase POMC gene expression in the pituitary; but CRH action is essential for this to result in increased secretion of ACTH. This may explain why, after withdrawal of chronic glucocorticoid treatment, reactivation of $\mathrm{CRH}$ secretion is a necessary prerequisite for recovery from suppression of the HPA axis.

J. Clin. Invest. 105:1269-1277 (2000).

\section{Introduction}

Adrenal glucocorticoid production is regulated by the complex integration of stimulatory and inhibitory signals that maintain homeostasis during stress (1-3). Secretion of adrenocorticotrophic hormone (ACTH) by the pituitary - the primary stimulus for glucocorticoid release - is modulated by the hypothalamic neuropeptides corticotropin-releasing hormone $(\mathrm{CRH})$ and vasopressin (VP); the release of these neuropeptides is in turn influenced by inputs from other regions of the central nervous system (CNS) (4-6). The degree of feedback inhibition by glucocorticoid in the CNS and at pituitary sites, in combination with hypothalamic neuropeptide release, thus defines the set point for plasma glucocorticoid levels (7-10). Dysregulated glucocorticoid production by the hypothalamic-pituitary-adrenal (HPA) axis frequently results in clinical pathology. For instance, autonomous ACTH production with excess glucocorticoid output, as occurs in Cushing's disease, results in obesity, hyperglycemia, hypertension, and osteoporosis (3). Alternatively, prolonged supraphysiologic glucocorticoid administration impairs the ability of the hypothalamus and pituitary to respond to acute glucocorticoid withdrawal, resulting in iatrogenic adrenal insufficiency. Recovery from this type of adrenal insufficiency can be prolonged. More subtle derangement of adrenal modulation in psychiatric illness $(11,12)$ is suggested by elevated plasma glucocorticoid levels in the setting of inappropriately elevated CNS concentration of $\mathrm{CRH}$.

Despite many physiologic and pharmacologic studies designed to dissect the contribution of glucocorticoidmediated negative feedback to $\mathrm{CRH}, \mathrm{VP}$, and proopiomelanocortin (POMC) gene expression and ACTH release, the threshold and mechanisms by which glucocorticoid insufficiency exerts its impact on the HPA axis remain uncertain. We have generated mice with com- 
plete CRH deficiency to facilitate in vivo analysis of HPA axis regulation and function $(13,14)$. Our previous studies have demonstrated markedly impaired adrenal responses to acute stressors such as restraint, ether, and fasting in the CRH-deficient (knockout [KO]) mice (14), as well as a failure to show the normal circadian increase in plasma glucocorticoid (15). Given their poor adrenal response to stress and marked adrenocortical atrophy (14), we were surprised to find normal basal (nonstimulated) plasma ACTH (15) and pituitary POMC immunoreactivity in CRH KO mice (14). In contrast to previous in vivo and in vitro studies $(16,17)$, this suggested that $\mathrm{CRH}$ may not be essential for POMC gene transcription, but may be critical for augmented release of ACTH from the pituitary in response to stress, circadian stimuli, and recovery of the HPA axis after the withdrawal of chronic glucocorticoid treatment.

\section{Methods}

Animal housing and manipulations. Wild-type (WT) and CRH KO mice were maintained under 12:12 hour light/dark (L:D) cycles and were fed ad libitum. Mice used for all studies were over 8 weeks old and were of a C57BL/6 $\times 129$ Sv genetic background maintained by breeding within our population. All mouse protocols were in accordance with National Institutes of Health guidelines and were approved by the Animal Care and Use Committees of Children's Hospital (Boston, Massachusetts, USA) and Washington University School of Medicine (St. Louis, Missouri, USA). Plasma for measurement of corticosterone, ACTH, and aldosterone was obtained by rapid retro-orbital phlebotomy into heparinized capillary tubes with a total time from first handling the animal to completion of bleeding not exceeding 30 seconds. Blood was collected on ice, and plasma was separated by centrifugation and stored at $-80^{\circ} \mathrm{C}$ until assay. Plasma concentrations of corticosterone (ICN Pharmaceuticals Inc., Costa Mesa, California, USA) and ACTH (Incstar Corp., Stillwater, Minnesota, USA) were determined by RIA as previously described (18). Plasma aldosterone was measured by RIA kit according to the manufacturer's specifications (Diagnostic Products Corp., Los Angeles, California, USA). For analysis of thymus and white fat, adult male and female mice of each genotype $(n=5-6)$ were evaluated at 4-6 months of age. Whole thymi and bilateral ovarian or testicular fat pads were isolated and placed on saline-saturated filter paper to remain hydrated until weighing.

ACTH content and gel filtration chromatography of pituitary extracts. Anterior pituitary (AP) and intermediateposterior pituitary (IP) were obtained from 8-week-old CRH KO and WT male mice between 0900 hours and 1100 hours as previously described (19). Tissues for the extraction were frozen on dry ice immediately after removal and were kept frozen at $-20^{\circ} \mathrm{C}$ until homogenization with $0.1 \mathrm{~N} \mathrm{HCl}(20)$. Part of the tissue extracts was reconstituted with $0.1 \mathrm{~N} \mathrm{HCl}$, applied to a Sephadex G-50 superfine column $(0.9 \times 60 \mathrm{~cm})$, and then eluted with $0.1 \mathrm{~N} \mathrm{HCl}$. One-milliliter fractions were collected and lyophilized.

The ACTH concentrations in the tissue extracts and chromatography fractions were determined by RIA as previously described (21). The ACTH antiserum used was a midportion to $\mathrm{COOH}$-terminal antiserum (915 $\mathrm{Ab}$ ) developed in our laboratory at a final dilution of 1:300,000. The sensitivity of the assay was $3 \mathrm{pg} /$ tube. The intra- and interassay variances were less than 5\% and $10 \%$, respectively. Cross-reactivities with corticotropin-like intermediate lobe peptide and $\alpha$ melanocyte-stimulating hormone were $12 \%$ and less than $1 \%$ on a molar basis, respectively. The ACTH content of the tissue was normalized for the protein level of the tissue determined by Bio-Rad Protein Assay (BioRad Laboratories Inc., Hercules, California, USA).

Adrenalectomy. CRH KO or WT male mice $(n=3$ per treatment group and genotype) underwent either (a) adrenalectomy, (b) adrenalectomy with subcutaneous implantation of a 21-day, sustained-release 1.6-mg corticosterone pellet (Innovative Research of America, Sarasota, Florida, USA), or (c) sham adrenalectomy via flank incision under aseptic conditions using tribromoethanol anesthesia (22). All mice underwent plasma sampling for
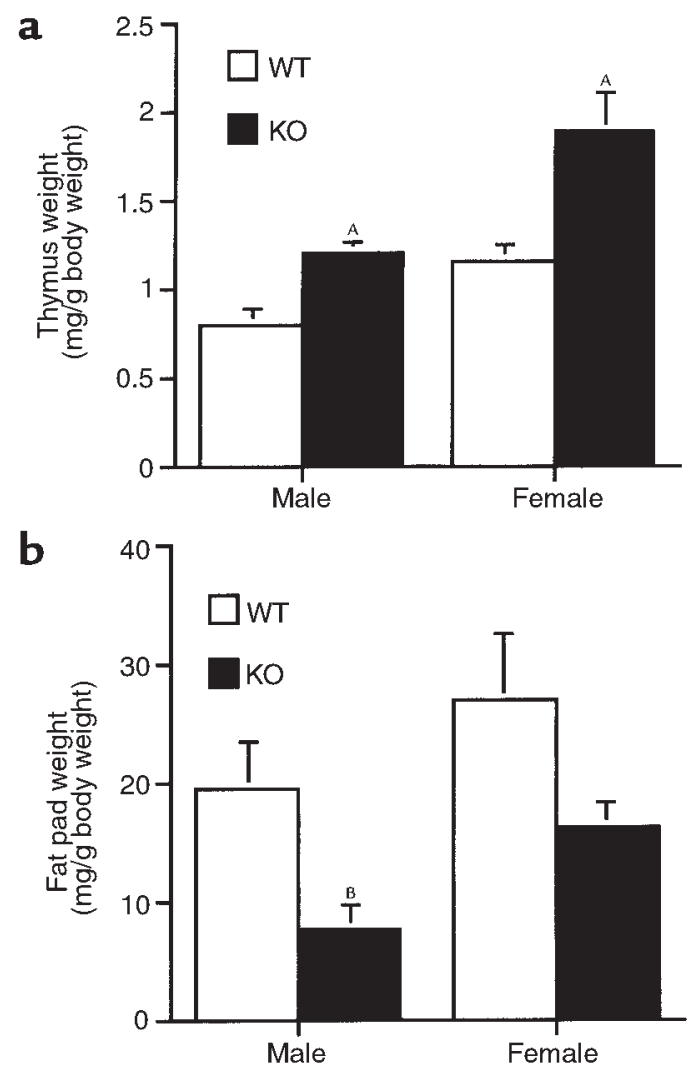

Figure 1

Evidence of chronic glucocorticoid insufficiency in $\mathrm{CRH}$-deficient mice. (a) Thymus weight normalized to total body weight for WT and $\mathrm{CRH}$-deficient $(\mathrm{KO})$ mice of each sex. ${ }^{A} P<0.01 \mathrm{vs}$. WT of same sex. (b) Testicular (male) or ovarian (female) fat pad weight normalized to total body weight. ${ }^{\mathrm{B}} P<0.05$ vs. WT male. 
ACTH measurement (at 7 days after adrenalectomy, 2-3 hours after lights-on) as well as harvest of hypothalamus and pituitary for immersion fixation (in 4\% paraformaldehyde in Dulbecco's PBS [D-PBS]) for in situ hybridization evaluation of VP and POMC mRNAs.

In situ mRNA bybridization. Hypothalami and pituitaries were harvested from the sham, adrenalectomy, and adrenalectomy plus pellet-replaced mice 7 days after surgery as described above $(n=3$ per genotype and treatment). After 24 hours immersion in $4 \%$ paraformaldehyde, hypothalami and pituitaries were cryoprotected in 10\% sucrose in diethyl pyrocarbonate-PBS. Samples were embedded in Tissue-Tek compound 4583 (Sakura Finetek USA Inc., Torrance, California, USA), cut into $10-\mu \mathrm{m}$ sections on a cryostat, and thaw mounted onto Superfrost plus slides (Fisher Scientific Co., Pittsburgh, Pennsylvania, USA). In situ hybridization used an $\left[\alpha-{ }^{3}{ }^{3} \mathrm{P}\right] U T P-l a b e l e d ~ 195-b a s e$ antisense riboprobe from the $3^{\prime}$ end of the rat VP gene (Taq I-Dra I) (23), or a 900-base antisense riboprobe from the mouse POMC cDNA $(24,25)$ by methods previously described (26). For pituitary, six sections from each treatment group and genotype were evaluated, with two sections imaged for densitometric analysis. For hypothalamus, four sections through the paraventricular nucleus were evaluated, with the two sections of peak intensity imaged for densitometric analysis. Hybridizing probes were quantitated by exposure of slides to Hyperfilm-ßMax (Amersham Life Sciences Inc., Arlington Heights, Illinois, USA) with densitometric analysis using NIH Image Software (http://rsb.info.nih.gov/nihimage), then were emulsion dipped, developed, and photographed under dark-field microscopy.

CRH stimulation testing. Intact WT or $\mathrm{KO}$ mice were tested in groups of five WT or CRH KO male or female mice. They were bled by retro-orbital phlebotomy 30 minutes after either no injection, intraperitoneal injection of 10 $\mu \mathrm{g} / \mathrm{kg}$ of mouse/human CRH (provided by G. Chrousos, National Institute of Child Health and Human Development, Bethesda, Maryland, USA), or intraperitoneal injection of vehicle (normal saline) at 2-3 hours after lights-on. Plasma ACTH and corticosterone concentrations were determined by RIA as described above. Adrenalectomized mice with and without corticosterone replacement were tested in groups of three to six WT or CRH KO mice. They were subjected to sham surgery, adrenalectomy, or adrenalectomy with subcutaneous implantation of a $40-\mathrm{mg} 25 \%$ corticosterone pellet, which provided approximately twice the physiologic replacement level (27). Seven days after surgery, all mice underwent retro-orbital phlebotomy followed by administration of $90 \mu \mathrm{g} / \mathrm{kg} \mathrm{CRH}$. Repeat plasma samples were obtained 40 minutes or 3 hours after injection. Corticosterone and ACTH were measured in all samples. Food intake as a function of corticosterone replacement in these mice has been discussed in a previous report (28).

VP stimulation testing. Groups of three to six WT or CRH KO female mice were bled by retro-orbital phlebotomy 10 minutes or 30 minutes after either (a) no

injection, (b) intraperitoneal injection of $0.5 \mu \mathrm{g}$ of arginine VP (Sigma, St. Louis, Missouri, USA), or (c) intraperitoneal injection of vehicle (PBS plus 0.3\% BSA) at 2-3 hours after lights-on. Plasma ACTH and corticosterone concentrations were determined by RIA.

Synthetic ACTH stimulation testing for aldosterone analysis. Synthetic ACTH 1-24 (Cortrosyn; Organon Inc., West Orange, New Jersey, USA) stimulation testing was performed 1-2 hours after lights-on in ad libitum-fed mice. Groups of male and female WT or CRH KO mice $(n=5)$

a
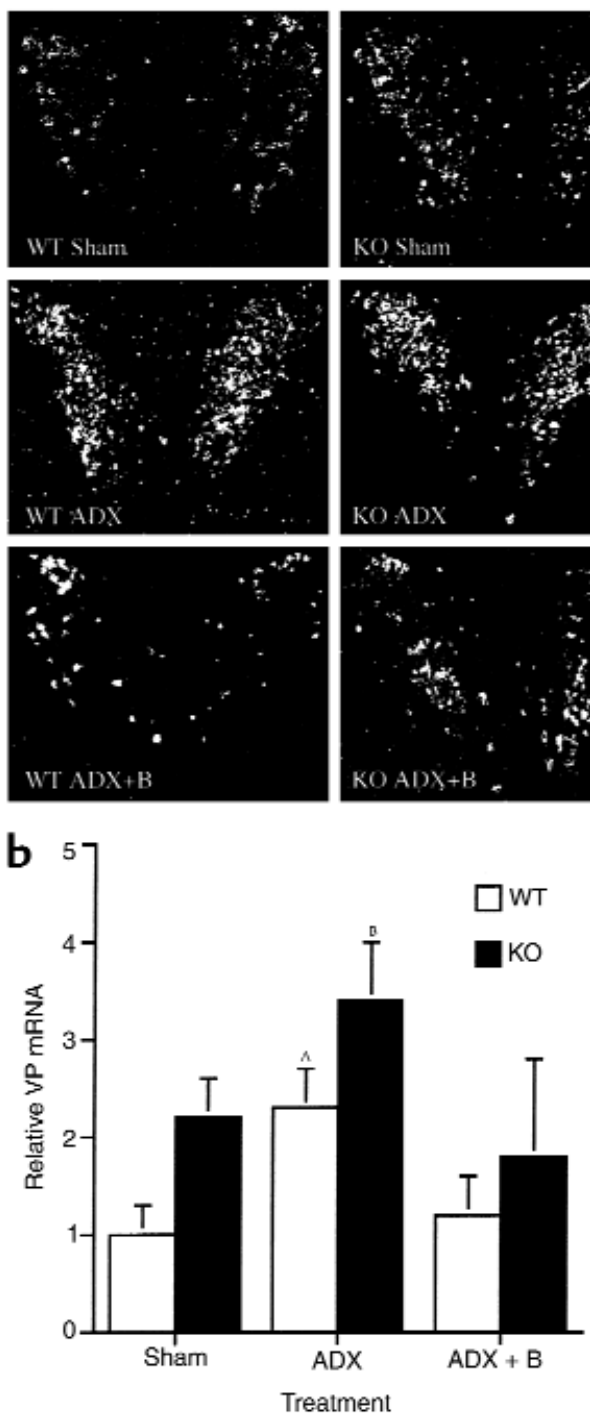

Figure 2

Effect of adrenalectomy (ADX) and low-dose corticosterone replacement on hypothalamic VP mRNA in WT and CRH KO mice. (a) Representative panels (from $n=3$ per genotype and treatment group) of emulsion-dipped coronal sections through the hypothalamic paraventricular nucleus subjected to in situ hybridization with a radiolabeled VP antisense riboprobe. Basal VP mRNA tended to be elevated in KO sham as compared with WT mice, and was further induced after adrenalectomy. VP mRNA was suppressed in WT and KO mice given low-dose corticosterone after adrenalectomy (ADX + B). (b) Quantitative analysis of VP mRNA hybridization signal intensity in the paraventricular nucleus. Pairwise comparisons: borderline significant increase WT ADX vs. WT sham ( $\left.{ }^{A} P=0.06\right) ;{ }^{B} P<0.05$ CRH KO ADX vs. WT sham. 

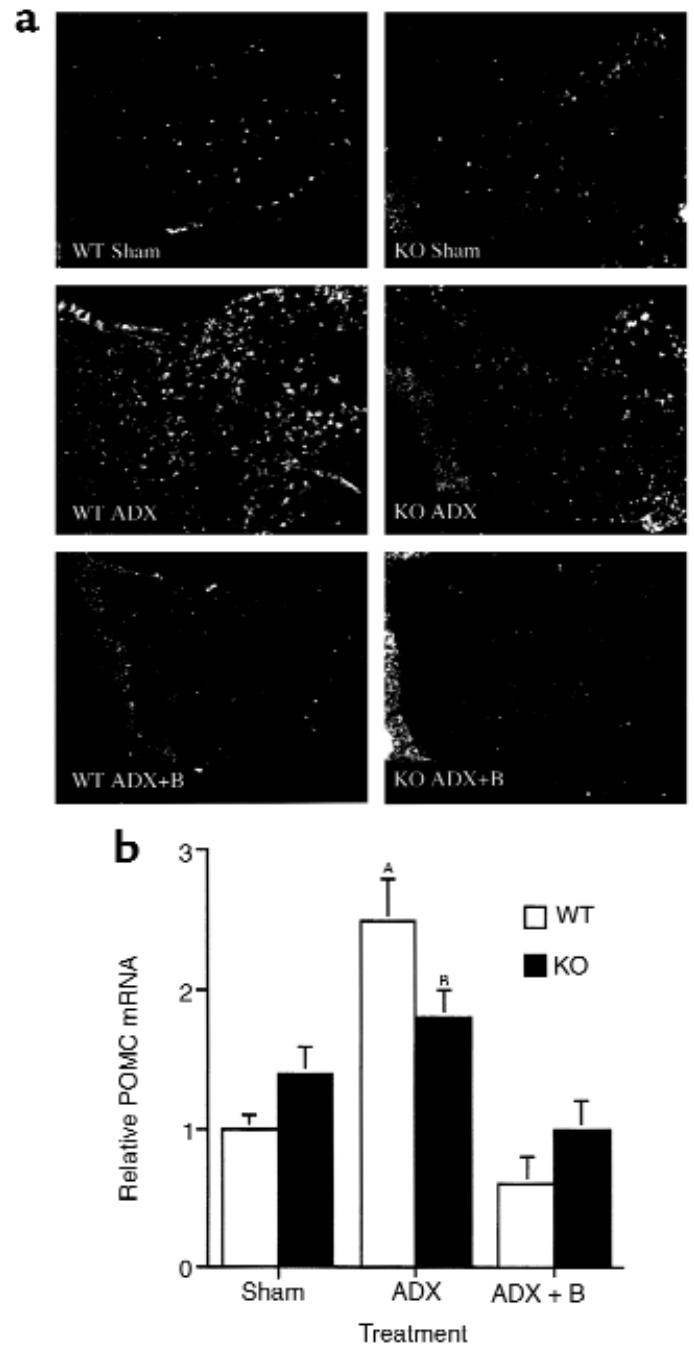

Figure 3

Effect of adrenalectomy (ADX) and low-dose corticosterone replacement on AP POMC mRNA in WT and CRH KO mice. (a) In situ hybridization of the pituitary with a radiolabeled POMC antisense riboprobe (representative of $n=3$ per genotype and treatment group). The neurointermediate lobe is oriented at the left side of each panel. Basal levels of POMC mRNA are equivalent in WT and KO mice, and increase after adrenalectomy in AP corticotrophs. The neurointermediate lobe of the pituitary demonstrated unchanged hybridization intensity before and after adrenalectomy. (b) Quantitative analysis of POMC mRNA hybridization signal intensity in the AP. ${ }^{A} P=0.01$ vs. WT Sham and WT ADX+B; ${ }^{B} P<0.05$ vs. WT Sham and WT ADX + B.

were bled by retro-orbital phlebotomy 60 minutes after either (a) no injection, (b) intraperitoneal injection of 10 $\mu \mathrm{g} / \mathrm{kg}$ Cortrosyn, or (c) intraperitoneal injection of vehicle (HEPES-buffered saline with 0.3\% BSA). Plasma aldosterone was measured.

Aldosterone supplementation. Three to six CRH heterozygous adult males per treatment group underwent either sham surgery or adrenalectomy followed by administration of normal saline with $0,1,5$, or 10 $\mu \mathrm{g} / \mathrm{mL}$ aldosterone as drinking fluid. Three days after adrenalectomy, all mice underwent retro-orbital phlebotomy for measurement of plasma aldosterone at 2 hours after lights-out in dim red light. Five days after adrenalectomy, a repeat blood sample was obtained at 2 hours after lights-on from all mice for measurement of plasma ACTH. Hypothalami were also isolated at this time and were immersion fixed in $4 \%$ paraformaldehyde, with processing for in situ hybridization performed as described above.

Statistical methods. Data are presented as the mean \pm SEM. Statistical analysis was by one-way ANOVA or unpaired $t$ test (two tailed) with significance accepted for $P \leq 0.05$.

\section{Results}

CNS and peripheral evidence of decreased glucocorticoid action in $\mathrm{CRH}$ KO mice. Thymus weight, a sensitive indicator of overall glucocorticoid status in rodents, increases with decreased exposure of this target tissue to glucocorticoid (27). We compared thymus size from adult CRH KO male and female mice with that of WT controls (Figure 1a). Thymus weight was significantly elevated in CRH KO mice of each sex, suggesting deficient glucocorticoid action in the $\mathrm{KO}$ mice. Depletion of white fat stores also occurs with glucocorticoid insufficiency (29), and, consistent with this, CRH KO males had significantly reduced white fat as compared with WT males (Figure $1 \mathrm{~b})$. This trend was also apparent in CRH KO females; although it did not achieve statistical significance, it is consistent with the milder deficit they exhibit in adrenocortical function (14).

Loss of glucocorticoid feedback to the CNS results in increased production of $\mathrm{VP}$ and $\mathrm{CRH}$ in the paraventricular nucleus of the hypothalamus (PVH) of WT rodents (30) and augmented ACTH release from the AP into the systemic circulation. CRH KO mice tended to have increased VP mRNA in the PVH relative to WT mice when evaluated by in situ hybridization, although the difference did not achieve statistical significance (Figure 2 , Sham; $P=0.10$ ). Because VP expression in the PVH of the mouse, unlike that of the rat, is not clearly separated into magnocellular and parvocellular components, a clearer increase in parvocellular VP expression in CRH KO mice may have been masked by magnocellular VP expression. Despite the absence of CRH, CRH KO mice demonstrated basal AP POMC mRNA levels similar to those in WT mice (Figure 3, Sham), and AP ACTH concentrations that were approximately $70 \%$ of those found in WT mice (Figure 4a). ACTH concentrations in the intermediate-posterior pituitary exhibited a similar trend between WT and KO mice, although the difference was not statistically significant (Figure 4b). Gel filtration chromatography of AP protein extracts demonstrated that the CRH KO AP tended to contain more, higher molecular weight compared with fully processed forms of ACTH (ratio of larger to smaller, fully processed forms of $1.35 \pm 0.23$ vs. $0.89 \pm 0.17$ in $\mathrm{KO}$ and WT pituitaries, respectively) (Figure 4, c and d). Thus, in the face of clear evidence of glucocorticoid deficiency in several peripheral and brain target tissues of CRH KO mice, their pituitary corticotrophs lack the expected increase in ACTH peptide content or secretion. This differential effect of 
glucocorticoid deficiency at the pituitary and other sites could be due to two possibilities. First, the normal rise in ACTH expression and secretion with glucocorticoid deficiency may require $\mathrm{CRH}$. Alternatively, the pituitary may be less sensitive than other tissues to the effects of glucocorticoid deficiency, such that the low but detectable levels of adrenal steroid (14) in CRH KO mice are sufficient to prevent pituitary activation of ACTH secretion. In the latter case, either of the two major steroids secreted from the rodent adrenal, corticosterone or aldosterone, might restrain ACTH expression in CRH $\mathrm{KO}$ mice. We anticipated that elevated aldosterone levels were not restraining ACTH secretion in CRH KO mice, as basal (14) and ACTH-stimulated (data not shown) plasma aldosterone are normal in these animals. To distinguish among the other possibilities, we examined the impact of combined CRH deficiency and adrenalectomy upon VP mRNA expression in the $\mathrm{PVH}$, and upon POMC mRNA expression and ACTH secretion from corticotrophs, without and with replacement with corticosterone or aldosterone, and after systemic administration of either CRH or VP.

Effects of combined CRH deficiency, adrenalectomy, and glucocorticoid replacement upon HPA axis activation. After adrenalectomy, VP mRNA in the PVH was elevated to the same extent in CRH KO and WT male mice (Figure 2, ADX). Adrenalectomized CRH KO and WT mice also had increased POMC mRNA expression in the AP, although the magnitude of the induction tended to be somewhat less in KO compared with WT mice (Figure 3, $\mathrm{ADX}$. . Despite the elevations in hypothalamic VP mRNA and AP POMC mRNA after adrenalectomy in CRH KO mice, no increase in plasma ACTH occurred in adrenalectomized $\mathrm{KO}$ mice, in contrast to the more than 10fold increase observed in adrenalectomized WT mice (Figure 5, ADX). The increases in VP mRNA and POMC mRNA in both genotypes, and in plasma ACTH in WT mice, were prevented by cotreatment with corticosterone $(\mathrm{ADX}+\mathrm{B}$ in Figures 2, 3, and 5) to maintain corticosterone levels at a normal morning diurnal nadir level of $2.2 \pm 0.7 \mu \mathrm{g} / \mathrm{dL}$ (WT mice) or $0.8 \pm 0.4 \mu \mathrm{g} / \mathrm{dL}$ (KO mice). In contrast, plasma ACTH levels remained markedly elevated in CRH-intact, adrenalectomized mice supplemented with aldosterone in amounts resulting in plasma levels 10- to 100-fold greater than normal. These levels only fell moderately at a plasma concentration of aldosterone (aldo) approaching that of corticosterone (plasma ACTH concentration | plasma aldosterone concentration): Sham: $194 \pm 20 \mathrm{pg} / \mathrm{mL} \mid 11.5 \pm 8.8 \mathrm{ng} / \mathrm{dL}$; ADX: $555 \pm 188 \mathrm{pg} / \mathrm{mL} \mid 0 \pm 0 \mathrm{ng} / \mathrm{dL}$ ( $P<0.05$ vs. Sham); ADX $\pm 1 \mu \mathrm{g} / \mathrm{mL}$ aldo: $512 \pm 280 \mathrm{pg} / \mathrm{mL} \mid 194 \pm 31 \mathrm{ng} / \mathrm{dL}$; $\mathrm{ADX} \pm 5 \mu \mathrm{g} / \mathrm{mL}$ aldo: $554 \pm 46 \mathrm{pg} / \mathrm{mL} \mid 568 \pm 119 \mathrm{ng} / \mathrm{dL}$ $(P<0.0001$ vs. Sham $) ; \mathrm{ADX} \pm 10 \mu \mathrm{g} / \mathrm{mL}$ aldo: $367 \pm 65$ $\mathrm{pg} / \mathrm{mL} \mid 1,497 \pm 517 \mathrm{ng} / \mathrm{dL}(P=0.01$ vs. Sham, $P=0.05$ vs. $A D X+5 \mu \mathrm{g} / \mathrm{mL}$ aldo). Similarly, the markedly elevated plasma aldosterone did not suppress PVH VP mRNA in ADX mice (data not shown). These data indicate that glucocorticoid, but not aldosterone, plays a significant role in negative feedback regulation of the HPA axis.
Effects of CRH and VP administration upon the HPA axis of CRH-deficient mice. Because adrenalectomy causes a qualitatively similar increase in hypothalamic VP mRNA and pituitary POMC mRNA in CRH KO and WT mice, but has markedly different effects upon plasma ACTH in the two genotypes (15) (Figure 5), we directly assessed the effect of CRH deficiency and replacement upon ACTH secretory capacity. We measured plasma ACTH in WT and CRH KO males and females 30 minutes after intraperitoneal injection of $10 \mu \mathrm{g} / \mathrm{kg}$ of CRH (Figure 6a). At this dose of $\mathrm{CRH}$, no significant difference in the rise in plasma ACTH among CRH KO males, KO females, or WT males was observed. WT females had a lower stimulated plasma ACTH level in comparison with KO males, KO females, and WT males, although their corticosterone response was equivalent to the WT males (Figure 6b). Despite the normal ACTH response to exogenous $\mathrm{CRH}$, plasma corticosterone was significantly diminished in the KO mice (Figure 6b), which was consistent with their blunted adrenal response to ACTH administration (15).

Despite near-normal ACTH peptide content, substantial releasable ACTH stores in CRH KO mice under basal conditions, and increased pituitary POMC gene expression after adrenalectomy, no change in plasma ACTH level occurs in response to relative or absolute

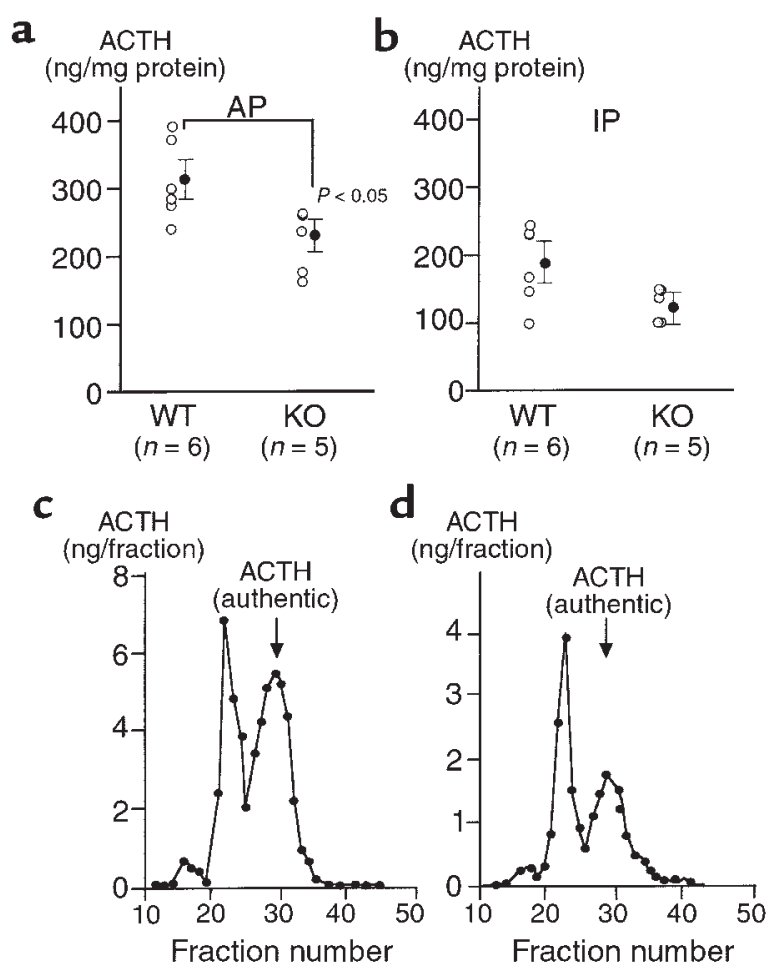

\section{Figure 4}

Pituitary ACTH content and processing in $\mathrm{CRH} K \mathrm{KO}$ and WT mice. Immunoreactive ACTH contents of (a) anterior pituitary (AP) and (b) intermediate-posterior pituitary (IP) from individual mice and means \pm SEM are shown. ${ }^{A} P<0.05$ vs. WT AP. Representative elution profiles of Sephadex G-50 gel filtration chromatography of ACTH extracted from AP of (c) WT and (d) CRH KO mice. 


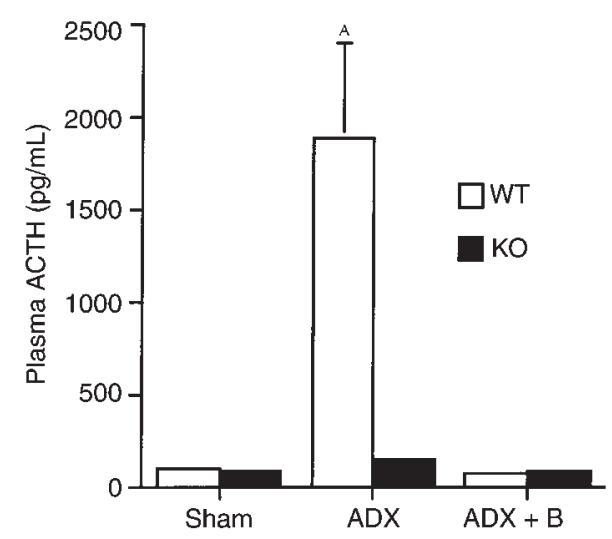

Figure 5

Effect of adrenalectomy (ADX) and low-dose corticosterone replacement (ADX + B) on plasma ACTH in WT and CRH KO mice. Plasma $A C T H$ increases to a much greater extent in WT than KO mice despite similar induction of pituitary POMC mRNA. Low-level glucocorticoid supplementation after adrenalectomy effectively returns plasma $A C T H$ to basal levels. ${ }^{A} P<0.05$ vs. all other groups.

glucocorticoid deficiency. This suggests that $\mathrm{CRH}$ is needed to create a synergism with the increased expression of hypothalamic VP (or with other factors associated with adrenalectomy) to effectively promote ACTH release from corticotrophs. To test this hypothesis, we evaluated the responses to bolus injection of $90 \mu \mathrm{g} / \mathrm{kg}$ of CRH in WT and KO male mice that underwent either adrenalectomy, adrenalectomy coupled with double physiologic corticosterone replacement (ADX $+2 \mathrm{XB}$ ), or sham surgery (Figure 7, a-d). As in Figure 6, the basal and post-CRH injection ACTH levels exhibited a similar pattern of regulation in sham $\mathrm{KO}$ and WT mice, although ACTH levels were higher overall in the KO mice $(P<0.05$ vs. WT at 40 minutes as well as 3 hours after injection). This was especially true 3 hours after injection (Figure 7a), possibly resulting from a lower level of glucocorticoid feedback in sham $\mathrm{CRH}$ KO versus sham WT mice (Figure 7c). In adrenalectomized WT mice, basal ACTH was markedly elevated compared with that in adrenalectomized $\mathrm{KO}$ mice, and was increased further after CRH administration (Figure $7 \mathrm{~b}$ ). The low basal level of plasma ACTH in adrenalectomized $\mathrm{KO}$ mice rose after $\mathrm{CRH}$ administration, such that at the 3-hour time point, adrenalectomized $\mathrm{KO}$ and adrenalectomized WT plasma ACTH concentrations were equally elevated (Figure 7b). As expected, no rise in plasma corticosterone occurred in adrenalectomized mice of either genotype after $\mathrm{CRH}$ administration (Figure 7d). Corticosterone pellet replacement to provide constant glucocorticoid levels that were approximately double the 24-hour mean (Figure 7c) resulted in a mildly reduced basal ACTH concentration and a profound blunting of plasma ACTH after CRH administration in both genotypes (Figure 7a).

We next asked whether $\mathrm{CRH}$ is required for the $\mathrm{ACTH}$ secretory response to VP, by comparing the ACTH and corticosterone responses to VP injection in WT and $\mathrm{KO}$ female mice. Evaluation of plasma ACTH concentration demonstrated equivalent, albeit relatively modest, increases in both $\mathrm{KO}$ and WT mice 10 minutes after injection in comparison with basal samples, although these were not statistically significant when compared with saline-injected controls (Figure 7e). Plasma ACTH concentrations returned to initial basal levels 30 minutes after injection in both genotypes. Despite the modest changes in ACTH secretion, WT female mice exhibited a marked and sustained increase in corticosterone after VP injection in comparison with vehicle-injected control WT mice (Figure 7f). No effect of VP injection on corticosterone production was apparent in the CRH KO mice, compared with vehicle-injected $\mathrm{KO}$ mice (Figure 7f).

\section{Discussion}

As evidenced by increased thymus size, decreased white fat stores, and elevated VP mRNA, CRH KO mice display chronically deficient glucocorticoid action on
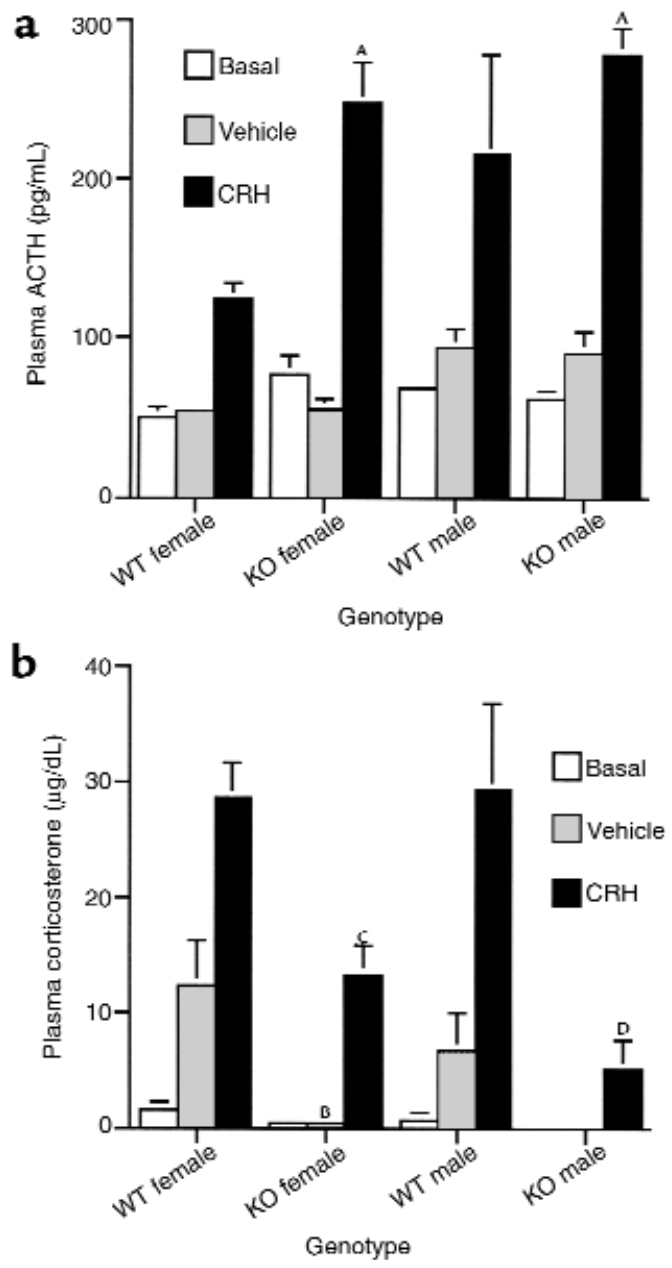

Figure 6

CRH stimulation of WT and CRH KO mice. (a) Plasma ACTH concentration 30 minutes after either no injection (basal), or intraperitoneal injection of vehicle or $10 \mu \mathrm{g} / \mathrm{kg} \mathrm{CRH}$. ${ }^{A} P<0.005$ vs. WT female $\mathrm{CRH}$. (b) Plasma corticosterone concentration after $\mathrm{CRH}$, vehicle, or no injection. ${ }^{\mathrm{B}} P<0.05$ vs. WT female vehicle; ${ }^{C} P<0.01$ vs. WT female $\mathrm{CRH}$; ${ }^{\mathrm{D} P}<0.05$ vs. WT male $\mathrm{CRH}$. 
a
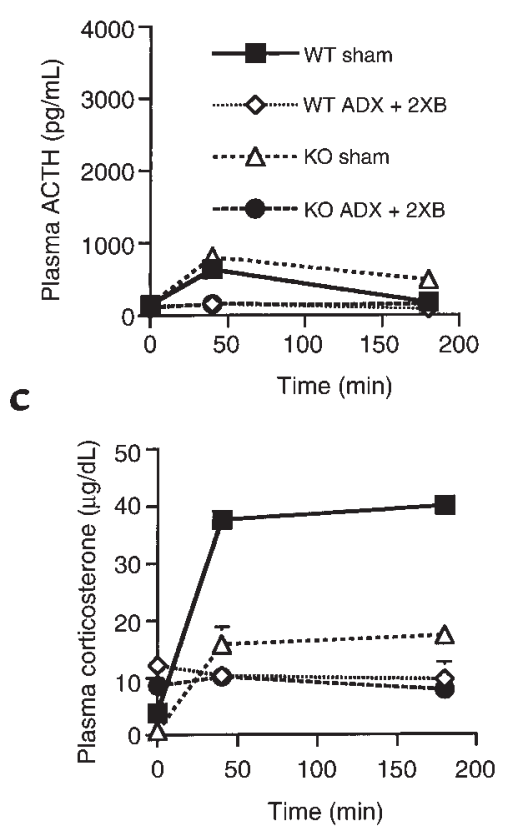

b

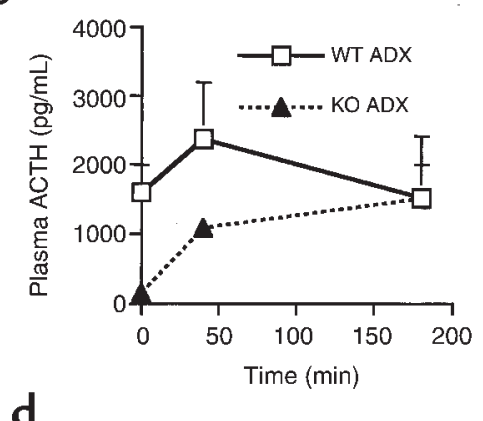

d

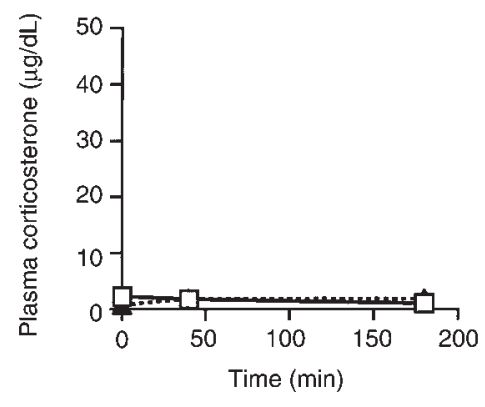

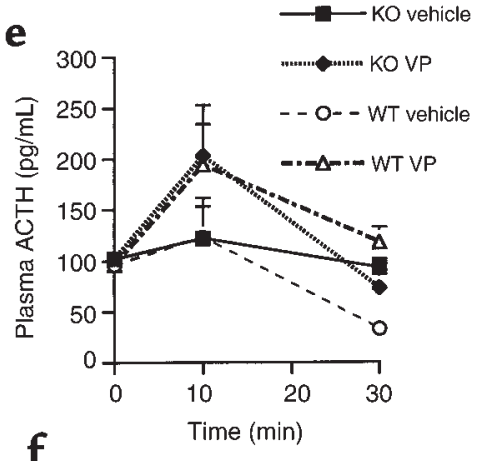

f

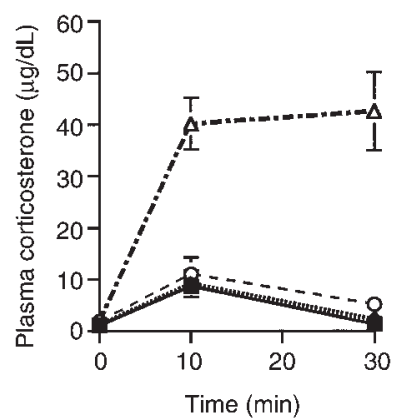

Figure 7

Stimulation of the HPA axis by CRH (a-d) or vasopressin (e and $\mathbf{f}$ ) in WT and CRH KO mice. Time course for plasma ACTH is shown for sham-adrenalectomized (sham) or adrenalectomized mice supplemented with constant-release corticosterone pellets delivering double the physiologic replacement ( $A D X+2 X B)(\mathbf{a})$, and for adrenalectomized (ADX) mice (b), after intraperitoneal injection of $90 \mu \mathrm{g} / \mathrm{kg} C R \mathrm{H}$. Respective time courses for plasma corticosterone are shown for the mice in $\mathbf{a}(\mathbf{c})$ and $\mathbf{b}(\mathbf{d})$. Plasma ACTH (e) and corticosterone (f) after injection of vehicle or VP. Plasma ACTH increases to a similar extent in KO and WT mice after VP compared with vehicle injection, although only the WT mice demonstrate a significant increase in plasma corticosterone.

these glucocorticoid-sensitive tissues. The elevated basal concentration of VP mRNA in the CRH KO mice is consistent with previous dose-response studies in rats that demonstrated elevation in parvocellular $\mathrm{CRH}$ mRNA with plasma corticosterone concentrations below $6 \mu \mathrm{g} / \mathrm{dL}$ (31). We have previously shown that both at circadian peak and during many acute physiologic stressors, plasma corticosterone in male CRH KO mice does not exceed $1-2 \mu \mathrm{g} / \mathrm{dL}(14,15)$. Adrenalectomy results in a further increase in hypothalamic VP mRNA in CRH KO mice, demonstrating their ability to respond to absolute glucocorticoid deficiency in a manner similar to that of WT mice. Anterior pituitary POMC mRNA expression is similar in WT and KO mice before adrenalectomy and increases in both genotypes after adrenalectomy. That POMC mRNA and plasma ACTH levels are not elevated in intact CRH KO mice may reflect an impaired response to relative glucocorticoid insufficiency with loss of CRH. However, the increase in POMC mRNA after adrenalectomy suggests that $\mathrm{CRH}$ is not absolutely required for changes in POMC expression in response to absolute glucocorticoid deficiency. The differences we observed in VP and POMC gene expression between adrenalectomized versus intact glucocorticoid-insufficient CRH KO mice could have been due to suppressive effects of aldosterone, increased sensitivity to low level glucocorticoid concentrations, or normal regulation of these endpoints by low glucocorticoid levels acting at high-affinity type I glucocorticoid (mineralocorticoid) receptors as suggested by studies in rats (32-34).

By subjecting mice to adrenalectomy with corticosterone pellet replacement (effectively clamping serum glucocorticoid at basal levels), we directly determined the capacity of low levels of glucocorticoid to restrict VP and POMC mRNA expression. These low levels of glucocorticoid very effectively blocked induction of both VP and POMC mRNAs in both genotypes, and serum ACTH increases in the WT mice after adrenalectomy. Based upon the similar responses of VP and POMC to the clamped basal glucocorticoid level in KO and WT mice, substantial differences in glucocorticoid sensitivity in the hypothalamus and pituitary of the KO mice are unlikely. In contrast, administration of aldosterone - producing plasma aldosterone levels 100 -fold greater than the usual physiologic range - to adrenalectomized mice was unable to significantly inhibit plasma ACTH secretion or increase in VP mRNA after adrenalectomy. Because aldosterone suppresses plasma ACTH in adrenalectomized mice only at very high concentrations (approaching those of circulating plasma corticosterone), our results suggest that occupancy of type II receptors or corticosterone-preferring type I receptors $(33,35,36)$ by very low level glucocorticoid 
concentrations - rather than by aldosterone - maintains the basal POMC mRNA level in the corticotrophs of CRH KO mice with intact adrenals.

Surprisingly, plasma ACTH does not increase in KO mice after adrenalectomy, despite the increase in pituitary POMC mRNA. These findings suggest that corticotrophs require $\mathrm{CRH}$ for secretion of $\mathrm{ACTH}$ but are less dependent upon $\mathrm{CRH}$ for increases in POMC mRNA levels resulting from enhanced transcription or mRNA stability. This hypothesis is further supported by the responses of CRH KO male and female mice to administration of exogenous CRH. Appearance of ACTH in the plasma was comparable to that in WT male mice and exceeded that in WT female mice, possibly resulting from the effects of glucocorticoid feedback in the WT female mice or enhanced CRH receptor sensitivity in CRH KO mice. Because the plasma ACTH concentration after $\mathrm{CRH}$ administration would be more affected by increased adrenal corticosterone production in intact WT mice than in $\mathrm{KO}$ mice, we performed a similar experiment in adrenalectomized WT and KO mice. Despite the markedly diminished baseline plasma ACTH in adrenalectomized $\mathrm{KO}$ as compared with WT mice, administration of $\mathrm{CRH}$ resulted in a similar incremental elevation between genotypes at 40 minutes after administration, and identical ACTH levels at 3 hours after injection. This again demonstrates ample pituitary stores of ACTH in the $\mathrm{KO}$ mice, and a requirement for $\mathrm{CRH}$ to cause its release. Administration of VP to CRH KO mice produced only a modest increase in plasma ACTH of a magnitude similar to WT mice, but it resulted in no significant rise in plasma corticosterone.

In CRH KO mice, induction of POMC mRNA occurs while the plasma ACTH level remains low. These findings suggest that in the absence of $\mathrm{CRH}$, peripheral glucocorticoid levels and/or hypothalamic neuropeptides (such as VP) can regulate POMC transcription or mRNA stability and ACTH production within the mouse corticotroph. This differs from previous investigations that implicated a critical role for $\mathrm{CRH}$ in augmenting POMC transcription, whereas VP primarily governed changes in ACTH release $(16,17)$. An increase in VP could serve to augment corticotroph ACTH secretion for the same degree of CRH stimulation, as suggested by reinstitution of a diurnal pattern of corticosterone production in $\mathrm{CRH} \mathrm{KO}$ mice when infused with a constant amount of CRH (15). Ultimately, however, stimulation by $\mathrm{CRH}$ remains essential for normal ACTH secretion into the circulation.

This may have clinical implications, because after the withdrawal of chronic supraphysiologic glucocorticoid treatment, it may take up to a year before the HPA axis recovers from the suppressive effects of this therapy (3). This suppression is likely due to an ongoing deficit in $\mathrm{CRH}$ - rather than in $\mathrm{ACTH}$ - secretion, as revealed by normal ACTH responses to $\mathrm{CRH}$ stimulation testing in patients being withdrawn from glucocorticoid treatment (37). We have previously demonstrated that $\mathrm{CRH}$ deficiency results in adrenal atrophy and hyporespon- siveness to a variety of stressors $(14,38)$. Our present findings may explain why, after withdrawal of glucocorticoid, activation of $\mathrm{CRH}$ secretion is a necessary prerequisite for recovery from suppression of the HPA axis; despite the elevation in pituitary POMC mRNA, which occurs in this setting, CRH is required for posttranscriptional events necessary for the release of ACTH and trophic support of the adrenal.

\section{Acknowledgments}

We thank members of the Muglia and Majzoub laboratories for helpful discussions during the course of these studies. This work was supported by grants from the National Institutes of Health (to L. J. Muglia, L. Jacobson, and J. A. Majzoub), National Alliance for Research on Schizophrenia and Depression (to L. Jacobson), and a Burroughs Wellcome Fund Career Development Award in the Biomedical Sciences (to L. J. Muglia).

1. Chrousos, G.P. 1995. The hypothalamic-pituitary-adrenal axis and immune-mediated inflammation. N. Engl. J. Med. 332:1351-1362.

2. Munck, A., Guyre, P.M., and Holbrook, N.J. 1984. Physiological functions of glucocorticoids in stress and their relation to pharmacological actions. Endocr. Rev. 5:25-44.

3. Orth, D.N., Kovacs, W.J., and Debold, C.R. 1992. The adrenal cortex. In Williams textbook of endocrinology. J.D. Wilson and D.W. Foster, editors. W.B. Saunders Co. Philadelphia, Pennsylvania, USA. 489-619.

4. Suda, T., et al. 1992. The role of corticotropin-releasing factor and vasopressin in hypoglycemia induced proopiomelanocortin gene expression in the rat anterior pituitary gland. Brain Res. 579:303-308.

5. Plotsky, P.M., Bruhn, T.O., and Vale, W. 1985. Hypophysiotropic regulation of adrenocorticotropin secretion in response to insulin-induced hypoglycemia. Endocrinology. 117:323-329.

6. Vale, W., Spiess, J., Rivier, C., and Rivier, J. 1981. Characterization of a 41residue ovine hypothalamic peptide that stimulates the secretion of cortricotropin and beta-endorphin. Science. 213:1394-1397.

7. Dallman, M.F., et al. 1987. Regulation of ACTH secretion: variations on a theme of B. Recent Prog. Horm. Res. 43:113-173.

8. Akana, S.F., et al. 1992. Feedback sensitivity of the rat hypothalamo-pituitary-adrenal axis and its capacity to adjust to exogenous corticosterone. Endocrinology. 131:585-594.

9. Dallman, M.F., et al. 1987. Characterization of corticosterone feedback regulation of ACTH secretion. Ann. NY Acad. Sci. 512:402-414.

10. Jacobson, L., Akana, S., Cascio, C., Scribner, K., and Dallman, M. 1989. The adrenocortical system responds slowly to removal of corticosterone in the absence of stress. Endocrinology. 124:2144-2152.

11. Gold, P.W., et al. 1986. Abnormal hypothalamic-pituitary-adrenal function in anorexia nervosa. Pathophysiologic mechanisms in underweight and weight corrected patients. N. Engl. J. Med. 314:1335-1342.

12. Gold, P.W., et al. 1986. Responses to corticotropin-releasing hormone in the hypercortisolism of depression and Cushing's disease. Pathophysiologic and diagnostic implications. N. Engl. J. Med. 314:1329-1335.

13. Muglia, L.J., Jenkins, N.A., Gilbert, D.J., Copeland, N.G., and Majzoub, J.A. 1994. Expression of the mouse corticotropin-releasing hormone gene in vivo and targeted inactivation in embryonic stem cells. J. Clin. Invest. 93:2066-2072.

14. Muglia, L., Jacobson, L., Dikkes, P., and Majzoub, J. 1995. Corticotropinreleasing hormone deficiency reveals major fetal but not adult glucocorticoid need. Nature. 373:427-432.

15. Muglia, L.J., et al. 1997. Impaired diurnal adrenal rhythmicity restored by constant infusion of corticotropin-releasing hormone in corticotropin-releasing hormone deficient mice. J. Clin. Invest. 99:2923-2929.

16. Antoni, F.A. 1993. Vasopressinergic control of pituitary adrenocorticotropin secretion comes of age. Front. Neuroendocrinol. 14:76-122.

17. Aguilera, G. 1994. Regulation of pituitary ACTH secretion during chronic stress. Front. Neuroendocrinol. 15:312-350.

18. Jacobson, L., and Majzoub, J.A. 1997. Protein malnutrition increases plasma adrenocorticotropin and anterior pituitary proopiomelanocortin messenger RNA in the rat. Endocrinology. 138:1048-1057.

19. Suda, T., et al. 1984. Effect of dexamethasone on immunoreactive corticotropin-releasing factor in the rat median eminence and intermediateposterior pituitary. Endocrinology. 114:851-854.

20. Suda, T., et al. 1984. Immunoreactive corticotropin and corticotropinreleasing factor in human hypothalamus, adrenal, lung cancer, and 
pheochromocytoma. J. Clin. Endocrinol. Metab. 58:919-924.

21. Suda, T., Demura, H., Jibiki, K., Tozawa, F., and Shizume, K. 1980. Anterior pituitary hormones in plasma and pituitaries from patients with Cushing's disease. J. Clin. Endocrinol. Metab. 51:1048-1053.

22. Hogan, B., Beddington, R., Constantini, F., and Lacy, E. 1994. Manipulating the mouse embryo: a laboratory manual. Cold Spring Harbor Laboratory Press. Cold Spring Harbor, New York, USA.

23. Carrazana, E.J., Pasieka, K., and Majzoub, J.A. 1988. The vasopressin mRNA poly(A) tail tract is unusually long and increases during stimulation of vasopressin gene expression in vivo. Mol. Cell. Biol. 8:2267-2274.

24. Roberts, J.L., Budarf, M.L., Baxter, J.K., and Herbert, E. 1979. Selective reduction of proadrenocorticotropin/endorphin proteins and messenger ribonucleic acid activity in mouse pituitary tumor cells by glucocorticoids. Biochemistry. 18:4907-4915.

25. Robinson, B.G., Mealy, K., Wilmore, D.W., and Majzoub, J.A. 1992. The effect of insulin-induced hypoglycemia on gene expression in the hypothalamic-pituitary-adrenal axis of the rat. Endocrinology. 130:920-925.

26. Muglia, L.M., et al. 1999. The 5 '-flanking region of the mouse adenylyl cyclase type VIII gene imparts tissue-specific expression in transgenic mice. J. Neurosci. 19:2051-2058.

27. Akana, S.F., Cascio, C.S., Shinsako, J., and Dallman, M.F. 1985. Corticosterone: narrow range for normal body weight and thymus weight and ACTH. Am. J. Physiol. 249:R527-R532.

28. Jacobson, L. 1999. Glucocorticoid replacement, but not CRH deficiency, prevents adrenalectomy-induced anorexia in mice. Endocrinology. 140:310-317.

29. Dallman, M.F., et al. 1993. Feast and famine: critical role of glucocorticoids with insulin in daily energy flow. Front. Neuroendocrinol. 14:303-347. 30. Sawchenko, P.E., and Swanson, L.W. 1985. Localization, colocalization, and plasticity of corticotropin-releasing factor immunoreactivity in rat brain. Fed. Proc. 44:221-227.

31. Swanson, L.W., and Simmons, D.M. 1989. Differential steroid hormone and neural influences on peptide mRNA levels in CRH cells of the paraventricular nucleus: a hybridization histochemical study in the rat. $J$. Comp. Neurol. 285:413-435.

32. Dallman, M.F., et al. 1989. Pharmacological evidence that the inhibition of diurnal adrenocorticotropin secretion by corticosteroids is mediated via type I corticosterone-preferring receptors. Endocrinology. 124:2844-2850.

33. de Kloet, E.R., et al. 1993. Brain mineralocorticoid receptor diversity: functional implications. J. Steroid Biochem. Mol. Biol. 47:183-190.

34. van Haarst, A.D., Oitzl, M.S., and de Kloet, E.R. 1997. Facilitation of feedback inhibition through blockade of glucocorticoid receptors in the hippocampus. Neurochem. Res. 22:1323-1328.

35. Jacobson, L., Brooke, S., and Sapolsky, R. 1993. Corticosterone is a preferable ligand for measuring rat brain corticosteroid receptors: competition by RU 28362 and RU 26752 for dexamethasone binding in rat hippocampal cytosol. Brain Res. 625:84-92.

36. Bradbury, M.J., Akana, S.F., and Dallman, M.F. 1994. Roles of type I and II corticosteroid receptors in regulation of basal activity in the hypothalamo-pituitary-adrenal axis during the diurnal trough and the peak: evidence for a nonadditive effect of combined receptor occupation. Endocrinology. 134:1286-1296.

37. Schulte, H.M., et al. 1984. The corticotropin-releasing hormone stimulation test: a possible aid in the evaluation of patients with adrenal insufficiency. J. Clin. Endocrinol. Metab. 58:1064-1067.

38. Jacobson, L., Muglia, L.J., Weninger, S.C., Pacak, K., and Majzoub, J.A. 2000. CRH deficiency impairs but does not block pituitary-adrenal responses to diverse stressors. Neuroendocrinology. 71:79-87. 